\section{EMBRYRIDDLE \\ Aeronautical University}

SCHOLARLY COMMONS

\section{International Journal of Aviation,} Aeronautics, and Aerospace

\title{
Advances in Composite Manufacturing of Helicopter Parts
}

Tobias A. Weber

Embry-Riddle Aeronautical University, webert1@my.erau.edu

Hans-Joachim K. Ruff-Stahl

Embry-Riddle Aeronautical University, ruffha@erau.edu

Follow this and additional works at: https://commons.erau.edu/ijaaa

Part of the Industrial Engineering Commons, Industrial Technology Commons, Manufacturing Commons, and the Technology and Innovation Commons

\section{Scholarly Commons Citation}

Weber, T. A., \& Ruff-Stahl, H. K. (2017). Advances in Composite Manufacturing of Helicopter Parts. International Journal of Aviation, Aeronautics, and Aerospace, 4(1). https://doi.org/10.15394/ ijaaa.2017.1153

This Article is brought to you for free and open access by the Journals at Scholarly Commons. It has been accepted for inclusion in International Journal of Aviation, Aeronautics, and Aerospace by an authorized administrator of Scholarly Commons. For more information, please contact commons@erau.edu. 
The percentage of composite parts used in airplanes and helicopters is constantly growing. For example, more than $50 \%$ of the weight of a Boing 787 and an Airbus A350XWB consist of carbon composites (Lukaszewicz, Ward \& Potter, 2011). The reason for this development is to be found in the superior material properties of carbon fiber reinforced plastics (CFRP) compared to standard aviation aluminum materials. These properties include corrosion resistance, high strength, and weight reduction potential (Federal Aviation Administration [FAA], 2012; Younossi, Kennedy \& Graser, 2001). In particular fatigue behavior makes carbon fiber reinforced plastics (CFRP) the preferred material for structural helicopter and airplane parts (Brauner, 2013; Younossi et al., 2001). In helicopters, examples for an increased use of CRFP include the new Sikorsky $\mathrm{CH}-53 \mathrm{~K}$ and the Airbus Helicopters $\mathrm{H} 160$. While the $\mathrm{CH}-53 \mathrm{~K}$ is the first $\mathrm{CH}-53$ model equipped with airframe side shells made from composite materials (Sikorsky, 2016), the H160 even introduces the first civil helicopter with a full composite airframe (Osborne, 2015).

In order to tap the full potential of CFRP in a helicopter, sophisticated manufacturing techniques must be applied. Yet, introducing these techniques in helicopter production is a costly endeavor and necessary investments have to be carefully weighed against expected returns. It is the purpose of this paper to provide this analysis.

Autoclave thermoset pre-impregnated (prepreg) composite technology has a long history in aviation and remains the major manufacturing method for structural composite parts in airplanes and helicopters (Elkington, Bloom, Ward, Chatzimichali \& Potter, 2015; Weber, Arent, Steffens, Balvers \& Duhovic, 2016; Weber \& Balvers, 2015). Unidirectional or woven fabric fiber layers are preimpregnated with resin to enable a fast and easy lay-up without the need to apply resin by hand. This manufacturing process provides the required part quality with high fiber volume fraction and enables the production of complex integral parts, such as the Airbus Helicopters H145 Fenestron ${ }^{\mathrm{TM}}$ shroud (Weber, Arent \& Steffens et al., 2016).

\section{Background of the Problem}

Nevertheless, there are disadvantages associated with autoclave manufacturing. Specifically, mandatory non-value-adding activities and longer manufacturing times caused by three factors: manual labor, longer autoclave cycles, and quality controls (Lindbäck, Björnsson \& Johansen, 2012; US Department of Energy, 2015). Manual labor is necessary for several reasons, such as the complexity of the parts including undercuts and sandwich cores, the lack of 
automation systems that can handle different types of prepreg materials, and the application of auxiliary materials as well as the required high accuracy. In particular, the required accuracy is hard to achieve by automated systems, when the part shape has multiple curvatures and undercuts (Elkington et al., 2015). Other non-value-adding activities arise as a result from the autoclave manufacturing routine that requires a sophisticated vacuum bagging of the part to avoid oxygen from reacting with the resin during cure. In addition to the working hours for vacuum bagging, auxiliary material has to be used, adding to the manufacturing costs. Further, after a part is de-molded, the mold has to be cleaned and release agents must be re-applied before the next part can be manufactured. Every single step is required to ensure the necessary level of part quality. Yet in spite of these detailed procedures, quality issues such as uneven curing, process induced deformations, fiber waviness, and porosity still remain an issue in today's autoclave manufacturing routines (Wang et al., 2009; Weber \& Balvers, 2015). Currently, manufacturers strive to overcome these challenges by looking for ways to improve part quality while at the same time reducing manufacturing times and costs to keep up their competitiveness on the world market (Weber \& Balvers, 2015). The major areas of costs reduction are labor cost, quality issues, material waste, reject rates, and diminished autoclave cycle times (Lindbäck et al., 2012).

\section{Identification of Possible Areas of Optimization}

The purpose of the autoclave is to consolidate and cure the previously laminated material. To accomplish this task, autoclaving takes place in a pressure vessel that is capable of applying a vacuum of approximately 0.2 to 0.8 bar absolute pressure directly to the mold and a surrounding pressure of up to 8 bar, which consolidates the prepreg material to its desired wall thickness and fiber volume fraction. In addition, the autoclave raises the internal temperature to $180^{\circ} \mathrm{C}$ to initiate the exothermic polymerization reaction of the thermosetting resin, the socalled curing. In order to provide the correct part shape, the prepreg plies are laminated onto molds made of mild steel, Invar ${ }^{\circledR}$ steel (FeNi36), or carbon fiber reinforced plastics (CFRP). To achieve the required results, the molds must be placed directly in the autoclave, thereby constituting the first dilemma of autoclave manufacturing: On the one hand the molds need to be stiff and stable to provide the correct part shape and to enable easy handling with a crane or forklift, on the other hand they should be as thin and light as possible for a fast and homogeneous heat-up (Weber, Arent, Steffens et al., 2016). Since the main source of heat transfer in the autoclave is forced convection, the molds should also be aerodynamically shaped to allow for high flow velocities and few flow obstructions, which in turn will result in a high heat transfer coefficient from the autoclave air to the mold (Johnston, 1997; Telikicherla, Altan \& Lai, 1994; Weber, Arent, Steffens et al., 
2016). Furthermore, the shape and type of the mold may produce thermos flasks that reduce the conduction of the applied heat from the outer mold surfaces to the composite part (see Figure 3; Weber, Arent, Münch et al., 2016; Weber, Arent, Steffens et al., 2016). Sometimes, thermos flasks cannot be avoided due to the complex shape of the manufactured part. In such a case, other methods for fast and homogeneous heat-up must be found. Clearly, the mold constitutes the first area of potential optimization.

The second area of optimization is the work process before the actual autoclave run. It deals with the manual labor involved in laminating a part and preparing a mold with the auxiliary materials. This manual work is highly dependent on the skills of the staff performing the task (Crawley et al., 2015). For example, the quality of some parts may vary depending on the experience level of the workers (Crawley et al., 2015). Due to the time and cost involved in training new personnel, some studies have suggested generating lamination guide lines, which ensure a reproducible part quality and reduce the training effort (Elkington et al., 2015; Crawley et al., 2015).

In fact, this knowledge is valuable, when it comes to developing machines to automate this process. While these machines are already available today, their range of application is rather limited, because using a machine for this process would require a change in part design and laminate stacking sequence, since only unidirectional tapes or tows can be placed by a machine. Automated systems, however, firstly eliminate the problem of variance in quality and secondly, the automated system combines lamination and pre-compaction in one single step (Lichtinger, 2014; Kollmannsberger, n.d.).

In theory, automated systems could therefore help to reduce manual labor, minimize material deposition times, reduce non-value adding steps, increase part quality, and ensure reproducible manufacturing results. Especially intermediate pre-compaction steps must be considered as non-value adding. Depending on part size, part shape, and lay-up routine as well as stacking sequence, an additional precompaction step may be required to avoid fiber wrinkling, aiming to reach full consolidation and thereby avoiding porosity (Lightfoot, 2013). Pre-compaction can be achieved by applying vacuum outside the autoclave or even increased pressure at room temperature within the autoclave. This additional step increases manufacturing time and cost significantly, since a separate vacuum bag has to be applied after about half of the lamination process is finished, autoclave time has to be available, and the auxiliary material of this intermediate vacuum bagging process is often lost completely (J.-C. Arent, Airbus Helicopters, personal communication, 2015). Hence, a combination of lamination and pre-compaction by using 
automated systems could be a suitable way to avoid additional pre-compaction steps in production. Furthermore, production waste is reduced by automated systems, because with higher precision in lamination, the edges of the laminated preform are much closer to the final part, thus reducing milling effort and waste (Younossi et al., 2001).

Another option to reduce manufacturing costs without introducing much technical innovation is shifting production capacities to best-cost-countries. At first glance, the lower labor cost in these countries should lower overall manufacturing costs; but other costs and additional risks must be examined. First of all, shifting the production to another country requires a considerable investment that must return the invested capital later (Shorten, Pfitzmann \& Kaushal, 2006). In addition, the efficiency, reliability, quality, and the transportation of parts to the final assembly line of the airplane or the helicopter must be calculated (Shorten et al., 2006). As a consequence, sophisticated supply chain management, logistics, and support systems must be either in place or must be developed first to avoid delays in production (University of Cambridge, 2001).

\section{Statement of the Problem}

The previously described problems may be summarized as follows: Improving the autoclave process will require new production methods and thus, large investments. While identifying possible improvement methods is rather simple, quantifying them poses a problem. Only a clear picture of the achievable benefits justifies large investments. Consequently, the benefit of potential reductions in manufacturing times, costs, and increases in part quality have to be assessed first and then weighed against the necessary investments.

More specifically, this paper provides a detailed cost-benefit analysis of the previously mentioned improvements by comparing the state-of-the-art autoclave manufacturing to advanced tooling and automated fiber placement technology in terms of potential reductions in manufacturing effort and improvements in part quality.

\section{Significance of the Problem}

In aviation, the percentage of parts made from composites as well as their complexity is constantly growing (see Figure 1). The new $\mathrm{CH}-53 \mathrm{~K}$ and the H160 (AH X4 in Figure 1) reveal that, especially in the helicopter sector, composite materials are in high demand due to their light weight as well as excellent fatigue and corrosion resistance (Mrazova, 2013; Younossi et al., 2001). These 
characteristics are highly advantageous for helicopters. The strength, stiffness, and light-weight capabilities of these parts are driven further to improve the performance of the helicopters (Red, 2008). To achieve this goal, individual parts become increasingly complex (Wiedemann \& Sinapius, 2012). Yet, innovations in CFRP part design can only be facilitated, if the new designs are manufactured at reasonable times and costs in order to compete with other, cheaper materials such as aluminum alloys (Shama Rao, Simha, Rao \& Ravikumar, 2015).

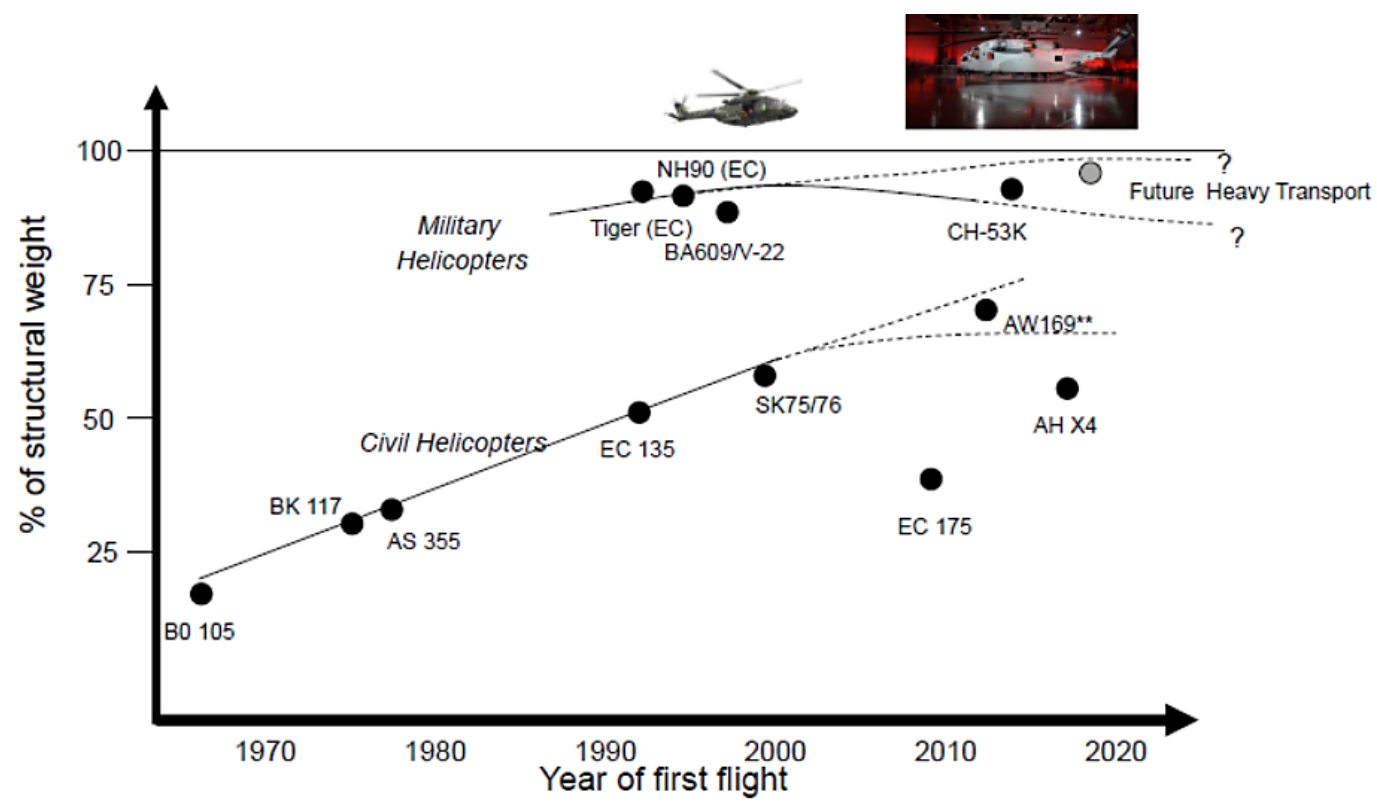

Figure 1. Percentage of parts made from composites (Weimer, 2014, Reprinted with permission.)

In addition to part design, helicopter production sites in the U.S. and Europe compete with low-cost countries that provide cheap labor and resources, which results in an increasing market share of products from these countries. To avoid the migration of composite part production to these parts of the world, an improvement of the current manufacturing routines is necessary. The goal is to enable composite production sites in Europe and the U.S. to offer their parts at competitive prices despite the higher labor costs. However, the transfer of some manufacturing capacities to low-cost countries might also be a valuable way to reduce costs while increasing the competitiveness of an aviation company at the same time. Especially in times of high demand and insufficient capacities at the original plant, it will be more sensible to outsource to a country with low-cost production rather than to enlarge the factory at non-justifiable cost in the home country. 


\section{The State of the Art in Autoclave Production}

\section{Tooling Technology}

The first area of improvement in autoclave production is advanced tooling technology. The current tooling design process is very often experience-based and limits mold optimization because the molds need to be tested before their performance can be evaluated and optimized (Weber \& Balvers, 2015; Weber, Arent, Münch et al., 2016; Weber, Arent, Steffens et al., 2016). Today, new manufacturing process simulation capabilities allow virtual mold testing within the design phase of the mold, thus enabling more sophisticated optimizations before the mold is actually produced (Brauner, 2013; Johnston, 1997; Weber \& Balvers, 2015; Xie, Liu, Zhang, Lovenzini \& Biserni, 2013). An important aspect of simulation-aided optimization is thermal improvement, which has a direct impact on manufacturing times and quality (Hudek, 2001; Mazarro \& Garcia, 2016; Weber \& Balvers, 2015; Telikicherla et al., 1994; Xie et al., 2013). Hudek (2001), for example, compares three different mold arrangements for the production of Lshaped profiles to validate his software for the prediction of autoclave heat transfer. From the data provided by Hudek (2001) it seems obvious that massive molds show considerably lower heating rates than thin-walled molds (compare Figure 2). Nevertheless, not all molds can be designed with thin walls because of stiffness and handling requirements.

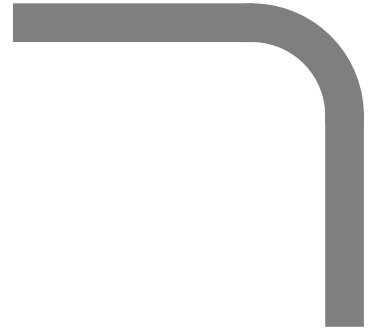

Mold A

Heat-up time to $175^{\circ} \mathrm{C}$ :

$147 \mathrm{~min}$

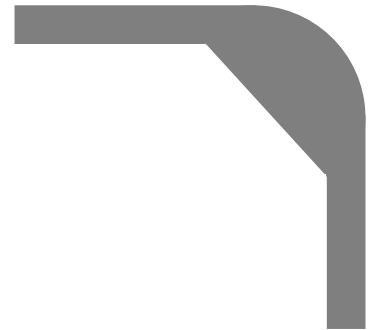

Mold B

Heat-up time to $175^{\circ} \mathrm{C}$ :

$148 \mathrm{~min}$

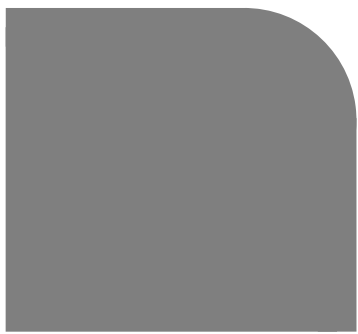

Mold C

Heat-up time to $175^{\circ} \mathrm{C}$ :

$180 \mathrm{~min}$

Figure 2. Comparison of three molds for the production of simple L-shaped profiles (adapted from Hudek, 2001.)

Very often, molds consist of a base plate with core segments placed on top of it to simplify handling and modification. To reduce weight, these cores are hollowed out. Since the vacuum bag surrounds the core completely, the hollowed out area beneath the core will be evacuated, leading to the same insulation that is 
present in a common thermos flask (see Figure 3 top; Weber, Arent, Münch et al., 2016; Weber, Arent, Steffens et al., 2016). Although weight and handling are improved, the hollowed out core might have a negative impact on heat-up time. In general, the parts of the mold, which are insulated by the thermos flask, show a much slower heat-up than the parts that are directly exposed to the autoclave air (Weber, Arent, Steffens et al., 2016). For the mold presented in Figure 3 top this is not quite so significant, since the part is mainly heated from the side of the vacuum bag. However, the central rib of the core section will stay cold until it is reached by heat conducted from the base plate and the part. This heat conduction from the part to the central core rib will influence the part negatively, leading to a reduced heatup in that area. The problem is more pronounced, when closed molds are used (see Figure 3 bottom). In this case, most of the heat must be conducted through the ribs or the walls of the core section to reach the composite part, because a direct heat intake into the part is not possible. All the heat necessary for curing must be conducted through the walls and ribs of the mold, which increases the heat-up time considerably.

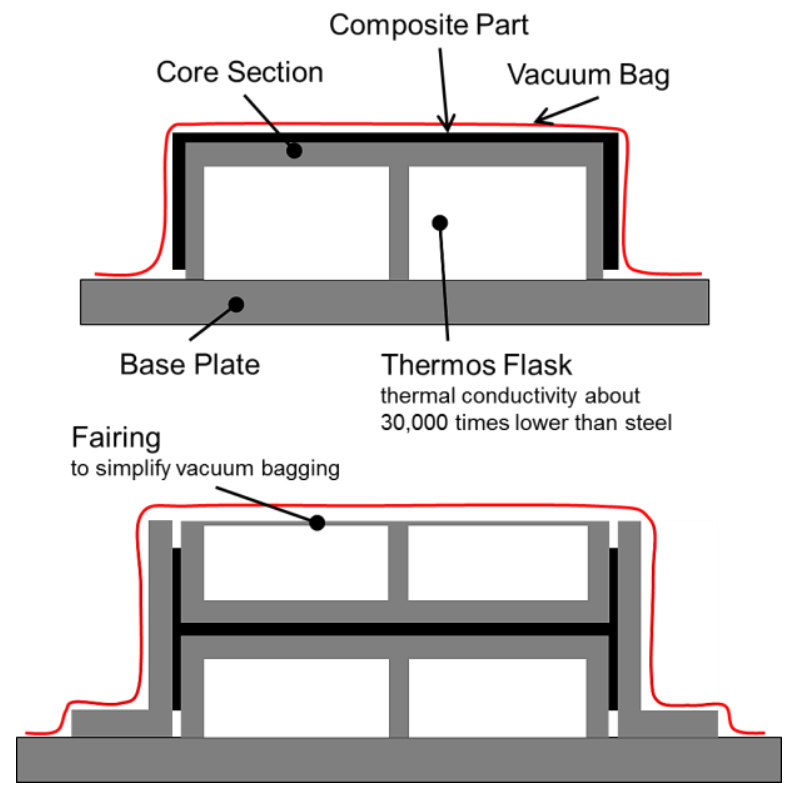

Figure 3. Standard molds with thermos flasks (top: open mold; bottom: closed mold) (adapted from Weber, Arent, Steffens et al., 2016; Weber, T. \& Balvers, J. M., 2015.)

Several improvements of the molds shown in Figure 3 are presented by Weber, Arent, Steffens et al. (2016). For the closed molds, the upper thermos flask can be eliminated by redesigning the upper core, making a fairing unnecessary for vacuum bagging (Weber, Arent, Steffens et al., 2016). Further improvements work 
for both closed and open molds. The base plate is avoided by redesigning the (lower) core to enable a direct connection to the support structure that provides the necessary stiffness as well as forklift rails or crane hooks (Weber, Arent, Steffens et al., 2016). Another possibility would be to separate the core section from the support structure as shown by Mazarro \& Garcia (2016). This separation does not only avoid thermos flasks but also allows the autoclave air to pass between core section and support structure, thereby improving the heating of core and part (Mazarro \& Garcia, 2016). But not all of the improvements shown in Figure 4 can be applied to all parts and molds. The complexity of the part and the molds themselves play an important role for the applicability of an optimization (J.-C. Arent, Airbus Helicopters, personal communication, 2015). Table 1 summarizes feasible achievements.

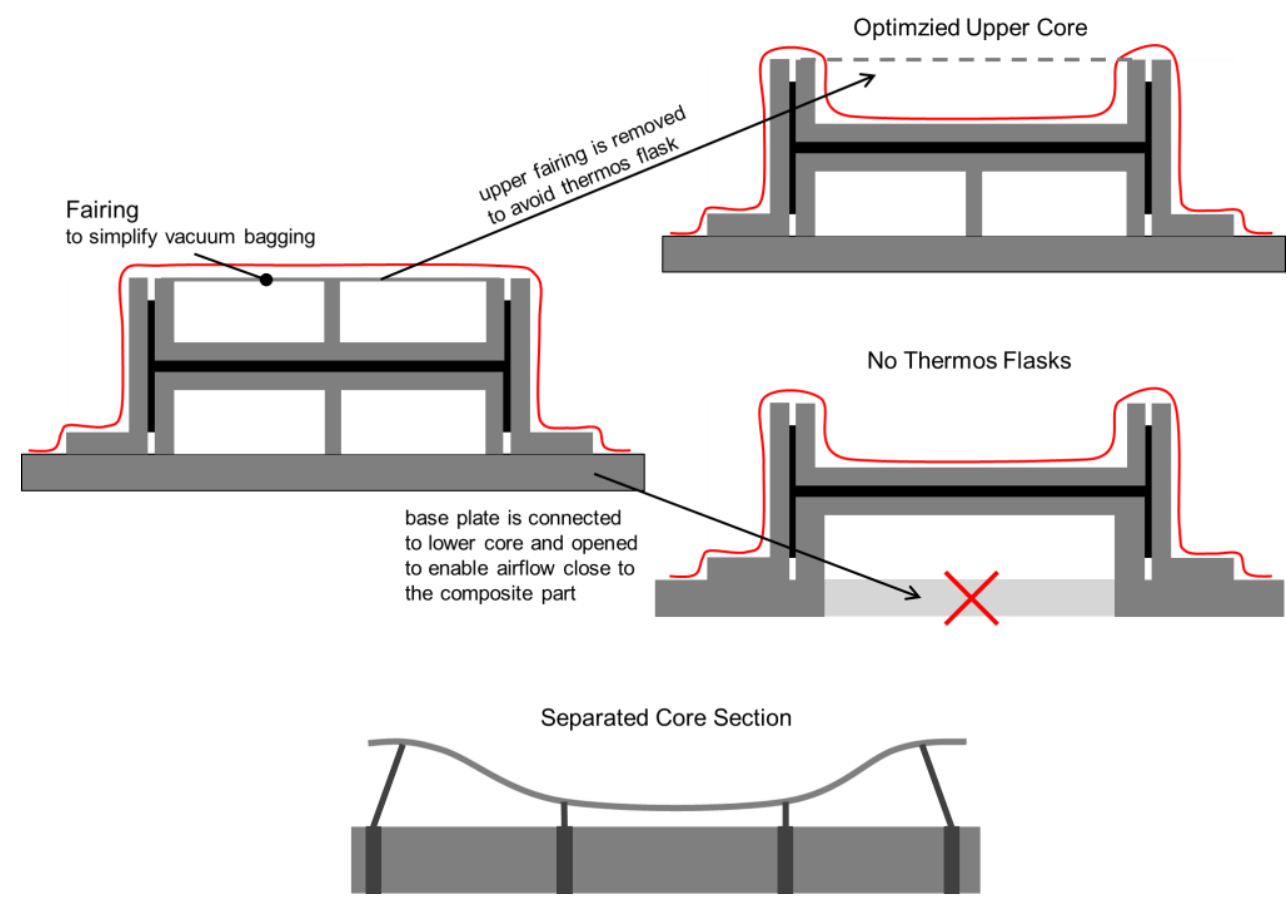

Figure 4. Mold improvements (adapted from Weber, Arent, Steffens et al., 2016; Weber, T. \& Balvers, J. M., 2015; Mazarro \& Garcia, 2016.)

In addition to reduced manufacturing times, part quality can be improved by the presented mold optimizations (Weber, Arent, Steffens et al., 2016). One quality measure is the final degree of cure and the internal stresses within the part. The final degree of cure influences strength and stiffness parameters (Brauner, 2013), while internal stresses lead to potential spring-in and process induced deformations (Brauner, 2013; Johnston, 1997). The higher the internal stresses 
actually are the greater will be the deformations after demolding. Since temperature gradients during cure result in thermal stresses frozen into the part, the temperature differences within the mold play a role in the development of internal stresses and process-induced deformations (Brauner, 2013; Johnston, 1997; Svanberg, 2002). Table 1 provides information on temperature differences within different molds. It is one purpose of this paper to determine, whether this reduction in temperature differences is statistically significant or not.

A major disadvantage of the mold optimization technique is that it may be applied to new molds only. Already existing molds cannot be optimized with this method, unless the molds are reworked. In some cases it may even be necessary to design and produce a completely new mold for an efficient thermal optimization (J.-C. Arent, Airbus Helicopters, personal communication, 2015). Yet, redesigning or reproducing an already existing mold is expensive and will therefore only be done, if the achieved part quality turns out not being within limitations (J.-C. Arent, Airbus Helicopters, personal communication, 2015). This points to an additional problem, which is directly linked to the autoclave manufacturing routine: Especially in helicopter manufacturing, small parts (less than one square meter) are rather common (J.-C. Arent, Airbus Helicopters, personal communication, 2015). Hence, for an efficient use of the autoclave capacities, these parts are grouped together in one autoclave run, under the condition that the autoclave is controlled by the mold requiring the slowest heating rate (J.-C. Arent, Airbus Helicopters, personal communication, 2015). As a result, the effectiveness of thermal mold optimization is not the same for all molds. More precisely, if only optimized molds are processed together, or if a mold is processed alone, the thermal optimization will have a positive effect. On the other hand, for molds that are processed in the same run with older, not optimized molds, the only effect will be an improved part quality. While the efficiency of the autoclave process would not increase, the increase in part quality will nevertheless indirectly reduce production costs and time, because fewer quality checks may be required (J.-C. Arent, Airbus Helicopters, personal communication, 2015).

\section{Advanced Lay-up Routines and Automated Fiber Placement}

Another promising area of improvement is the manual lay-up technique. In helicopter manufacturing, almost all composite parts are laminated by hand, which results in high labor costs per part (Hoa, 2014). Depending on the size, weight, and complexity of the part, manual lay-up can amount to about $42 \%$ of the total manufacturing costs (Ma, 2011). A faster, more efficient routine could reduce the working hours per part and therefore the labor costs (Crawley et al., 2015; Elkington et al., 2015). 
Table 1

Possible improvements with optimized molds (in italics: standard configurations without any kind of optimization)

\begin{tabular}{|c|c|c|c|}
\hline & Source & $\begin{array}{l}\text { Approximate } \\
\text { Heat-up Time }\end{array}$ & $\begin{array}{l}\text { Approximate } \\
\text { Temperature } \\
\text { Difference }\end{array}$ \\
\hline Mold A & Hudek, 2001 & $147 \mathrm{~min}$ & N/A \\
\hline Mold B & Hudek, 2001 & $148 \mathrm{~min}$ & N/A \\
\hline Mold C & Hudek, 2001 & $180 \mathrm{~min}$ & $N / A$ \\
\hline Standard Mold (1) & $\begin{array}{l}\text { Weber, Arent, } \\
\text { Steffens et al., } \\
2016\end{array}$ & 353 min & $26^{\circ} \mathrm{C}$ \\
\hline Optimized Upper Core (1) & $\begin{array}{l}\text { Weber, Arent, } \\
\text { Steffens et al., } \\
2016\end{array}$ & $311 \mathrm{~min}$ & $14^{\circ} \mathrm{C}$ \\
\hline No Thermos Flasks (1) & $\begin{array}{l}\text { Weber, Arent, } \\
\text { Steffens et al., } \\
2016\end{array}$ & $300 \mathrm{~min}$ & $9^{\circ} \mathrm{C}$ \\
\hline Typical Helicopter & Weber, Arent, & $330 \mathrm{~min}$ & $65^{\circ} \mathrm{C}$ \\
\hline Structure & $\begin{array}{l}\text { Steffens et al., } \\
2016\end{array}$ & & \\
\hline Improved Helicopter & Weber, Arent, & $252 \mathrm{~min}$ & $25^{\circ} \mathrm{C}$ \\
\hline Structure & $\begin{array}{c}\text { Steffens et al., } \\
2016\end{array}$ & & \\
\hline Standard Mold (2) & $\begin{array}{c}\text { Weber \& } \\
\text { Balvers, } 2015\end{array}$ & $240 \min$ & $N / A$ \\
\hline Optimized Upper Core (2) & $\begin{array}{c}\text { Weber \& } \\
\text { Balvers, } 2015\end{array}$ & $203 \min$ & $\mathrm{N} / \mathrm{A}$ \\
\hline Standard Mold (Invar) & $\begin{array}{c}\text { Weber, Arent, } \\
\text { Steffens et al., } \\
2016\end{array}$ & $441 \min$ & $53^{\circ} \mathrm{C}$ \\
\hline $\begin{array}{l}\text { Optimized Upper Core } \\
\text { (Invar) }\end{array}$ & $\begin{array}{l}\text { Weber et al., } \\
2016\end{array}$ & $273 \min$ & $13^{\circ} \mathrm{C}$ \\
\hline
\end{tabular}

A major problem of manual labor is that each worker employs a slightly different procedure to laminate a part, making it difficult to identify the optimal manual lay-up process (Hoa, 2014). Consequently, manufacturing times as well as part quality will vary slightly depending on the person performing the lamination (Crawley et al., 2015). To improve manual lay-up processes, expert knowledge 
from experienced laminators must be gained, aiming to identify the fastest lay-up routine. This knowledge can then be used to reduce manufacturing times and to achieve a high part quality that is also consistently reproducible (Crawley et al., 2015). In addition, the gained knowledge enables better and more effective training of new workers, which itself helps to reduce non-recurring costs because training time can be cut down (Crawley et al., 2015; Elkington et al., 2015). However, the achievable cost reductions are limited, since the labor intensive manual work and possible pre-compaction cycles remain. Besides, human error significantly influences quality and work speed, too.

One possible way to reduce the impact of human limitations is the introduction of automated manufacturing systems such as the automated fiber placement (AFP) system. First of all, the human limitations in material deposition speed can be exceeded by more than four times. While manual lay-up reaches a mean deposition rate of about 1.0 to $1.2 \mathrm{~kg} / \mathrm{h}$, the mean deposition rate for AFP exceeds $4.5 \mathrm{~kg} / \mathrm{h}$ at comparable accuracy (Hoa, 2014; Lukaszewicz et al., 2012). Consequently, a higher deposition rate achieved by the AFP will reduce the overall manufacturing time of the part. Yet other time consuming factors such as the time needed to apply auxiliary material, the autoclave cycle time, and the de-molding and cleaning times remain unaffected (Lukaszewicz et al., 2012). Compaction applied during AFP on the tows that are placed on the mold further reduces or avoids time needed for pre-compaction steps. In sum, a cost reduction of up to $43 \%$ is reported by Lukaszewicz et al. (2012).

Additional cost reductions are possible by introducing an automated inspection as part of the AFP process (Sloan, 2015). Grimshaw, Grant, and Diaz (n.d.) mention a theoretical reduction in man-hours of up to $85 \%$ for automated tape laying (ATL), which is similar to the AFP procedure except for the size of the prepreg strips. Overall, if manual labor accounts for about $42 \%$ of the costs, a reduction of $85 \%$ in manual labor would result in an overall total cost reduction of about 35\% (Grimshaw et al., n.d.; Lindbäck et al., 2012). Younossi et al. (2001) illustrate the costs for manual lay-up (with and without optical laser ply alignment) and automated fiber placement by comparing three different part complexities. Their comparison is simplified and partly reprinted in Table 2.

In contrast to these numbers, Dequine and Rush (2014) predict a cost reduction of only $13 \%$ for a rather simple shell structure, which is less than half of what is estimated by Younossi et al. (2001) and only a third of the savings presented by Lukaszewicz et al. (2012). While they predict a reduction in manual labor of only 54\%, Dequine and Rush (2014) point out that, with an increasing number of 
produced units, the positive effect of an automated system will increase proportionally.

Table 2

Comparison of costs between hand lay-up and AFP [adapted from Younossi et al. (2001)]

\begin{tabular}{lccc}
\hline Fabrication Process & Simple Part & Medium Part & Complex Part \\
\hline Hand lay-up with optical laser & 1.0 & 1.45 & 1.73 \\
ply alignment & 0.64 & 1.18 & 1.55 \\
AFP & $36 \%$ & $19 \%$ & $10 \%$ \\
Reduction with AFP & & &
\end{tabular}

In addition to a reduction in manufacturing times and adjacent costs, AFP increases part quality, too. Moreover, these results are reproducible, the quality of the produced parts is independent of operator skill (Hoa, 2014; Lukaszewicz et al., 2012), and a decreased work speed or accuracy during night shifts is no longer a problem. Negative human influence is even further minimized, because the required stacking sequence is produced automatically by a programmed machine (Lukaszewicz et al., 2012) and reject rates of entire AFP laminated parts are usually lower than the 5\% encountered for manual lay-up (Grimshaw et al., n.d; Ma, 2011). Besides these direct outcomes, there are a number of positive second-order effects. For example, a constant and reproducible quality decreases the required effort for quality assurance and associated costs, which account for about $25 \%$ of the total costs (Dequine \& Rush, 2014). Consequently, a 50\% reduction in quality assurance should result in a decrease of the total cost by an additional $12.5 \%$ (Dequine \& Rush, 2014).

The use of AFP also reduces manufacturing waste. Manual lay-up often results in a waste rate of about $15 \%$ to $30 \%$ (Grimshaw et al., n.d; Ma, 2011). Automated processes, in contrast, can reduce the rate to $5 \%$ with a positive effect on material costs (Grimshaw et al., n.d). On the other hand, Dequine \& Rush (2014) show that the use of AFP will result in higher overall material costs than hand layup, because the sophisticated AFP tows are simply more expensive than the conventional prepreg material.

In another sector of composites use, the manufacturing of wind turbine rotor blades, a reduction in labor costs and overall manufacturing costs when using AFP cannot be proven (Schubel, 2012). Possible cost reductions in this sector might be 
limited to a reduction in rejection rates by improving quality and tighter dimensional tolerances (Dassault Systems, 2014; Schubel, 2012).

The greatest disadvantage of AFP may be seen in its initial investment, with some systems costing up to US \$6M depending on their complexity (Goel, 2000). As far as the complete production process is concerned, Dequine \& Rush (2014) show that the equipment cost for AFP technology is more than three times higher compared to a corresponding hand lay-up production, in so far as an autoclave is already available. This large initial investment may not justify AFP, if its cost reduction potential stays behind expectations.

\section{Low-cost Countries and Make-or-buy Decision Making}

A more radical solution for cost reduction would be shifting the production to low-cost or best-cost countries. Depending on the complexity of the work that is going to be transferred, various countries may be chosen and varying reductions are possible in each country (Vestring et al., 2005). Since aviation parts made of composites are considered high-tech parts, countries like Poland, Brazil, Mexico, or China are relevant locations (Vestring et al., 2005). The labor costs in these countries range from $\$ 2$ per hour to approximately $\$ 4$ per hour, which is significantly less than the hourly rate in Germany or the United States, where labor costs for production workers can be as high as $\$ 50$ to $\$ 60$ per hour (Vestring et al., 2005). However, shifting production capacities to another country is not an easy task. Manufacturing facilities must be already available or built, equipment may have to be moved and installed, and workers trained, etc. (Vestring et al., 2005). Besides, the original plant in the home country may have to be closed, adding to the relocation investment and causing political problems. Vestring et al. (2005) predict costs as much as 200,000 Euros per laborer in countries such as Germany or the United States. Hence, a careful analysis of all factors is mandatory to evaluate whether theoretical cost reduction will actually result in a return of investment within a reasonable time frame (Vestring et al., 2005).

In case the production of parts is actually moved to a low-cost country, logistics become a major factor. The goal is to keep up the productivity and work speed at the final assembly lines that often remain in the respective home country (Vestring et al., 2005). This means that just-in-time delivery and a perfectly adjusted multimodal transportation system are required to avoid an increase in overall manufacturing times. In addition, the transport of multiple parts generates costs, which must be included in the total cost of transferring production units to a location offering reductions in manufacturing costs (Jacobs \& Chase, 2011; Shorten et al., 2006; University of Cambridge, 2001). Even if a significant cost reduction 
can be achieved, manufacturing plus transportation times might actually be higher than at the original plant, while part quality might diminish (Vestring et al., 2005). As a result, quality costs may even increase until the new personnel is familiar with the manufacturing procedures and has gained the required expertise for high quality production (Committee on the Offshoring of Engineering, 2008).

An alternative to both production and shifting one's production site can be to buy parts on the market. Certain (international) suppliers may be able to offer the same part at a lower price. Several factors allow suppliers to offer parts at lower prices. They could be more specialized in producing a product (Jacobs \& Chase, 2011; Shorten et al., 2006), or the supplier may already have a facility in a low-cost country, which minimizes initial investment. Furthermore, choosing the right supplier could even provide access to the supplier's manufacturing technologies without the need for investment in research and development or new machinery (Shorten et al., 2006; Vestring et al., 2005).

The major disadvantage of buying parts from external suppliers is the required effort for coordination and assessment (Shorten et al., 2006). Auditing the supplier to ensure that all parts have sufficient quality is just as important as a coordination of timely production and delivery, so that the final assembly line can work without disruptions (Jacobs \& Chase, 2011; Shorten et al., 2006). Next, the final assembly and the production of all parts (including those from external suppliers) must be synchronized to avoid storage times and costs (Jacobs \& Chase, 2011). Third, a smooth logistics system must be capable of handling the size and number of the parts plus delivery at the correct times. Finally, the supplier itself must be carefully selected, because know-how of the design of innovative parts and innovative production techniques must be protected and should not leave the company (Shorten et al., 2006). Therefore, the decision making process about what to make and what to buy is time consuming and costly by itself (Shorten et al., 2006).

Another disadvantage is the resulting multi-facetted dependence on the supplier to include the risks of lower than expected quality, delays in delivery, and reliability issues. In cases where the supplier is the only source of a certain part, even the final assembly of a helicopter will be exposed to serious risks (Jacobs \& Chase, 2011). A recent case study concerning problems with suppliers has been provided by Volkswagen AG in the summer of 2016. Several suppliers stopped delivering parts, because they wanted to negotiate better business terms, causing a standstill of several assembly lines (Cremer, 2016; Hull, 2016) and ultimately serious financial losses. 


\section{Statement of the Hypothesis}

At first glance, the literature suggests that the above mentioned approaches will reduce manufacturing effort. Therefore, the hypothesis is that an improved or automated prepreg production method correlates with a significantly reduced manufacturing effort and an increased quality of composite helicopter parts. If the hypothesis is accepted and a correlation exists, the gathered data will be used to provide recommendations on the effectiveness of the different improvement approaches. If no correlation is found, the conclusion must be that these improvements are not worth the implementation cost.

\section{Method}

\section{Sources of Data}

Exact data concerning manufacturing times and costs are difficult to obtain. For most of the companies in the aviation and automotive industries, these data sets are confidential. Therefore, most information is obtained from universities and research institutes. An intensive literature review provides the necessary quantitative data for the evaluation of the different improvement methods.

\section{Reliability, Validity, and Comparability of the Data Sets}

The data obtained from literature is reliable, since most of the papers and presentations used come from peer reviewed scientific journals and conferences. The validity of the data on the other hand is slightly impaired by several factors. First of all, the data is mostly obtained from research projects, universities, and research institutes but not directly from the industry. Especially the manufacturing cost and time of a serial production can only be estimated. In research projects usually prototypes are tested, allowing only an estimation of the true later costs. On an industrial scale, in contrast, a learning curve is expected, because workers will become more efficient and processes optimized during the course of production. Neither the learning curve nor the process improvements are considered in academic settings, when only a prototype is produced in the framework of a research project.

The validity and particularly the ability to transfer organizational knowledge to a large scale production are further impaired by the fact that the number of available data sets is rather low. Where AFP is concerned, no direct comparison between hand lay-up and AFP using the same part could be found. A direct comparison of the different concepts, as done for the thermal optimization, was not 
possible for the AFP system. Another problem that reduces the validity and comparability of the data is the fact that most of the numbers provided for cost reduction do not reveal the needed background information for an objective evaluation. In addition, there is no information on the types of costs considered, although cost reduction percentages are given. First, while Dequine and Rush (2014) e.g. do not consider the reduction in quality assurance costs, other researchers may have included them in their estimates, yet without clearly listing them. Second, it has been pointed out that the actual cost reduction through AFP depends on the number of parts that are going to be produced. Despite these limitations, various production set-ups and improvement methods were quantitatively analyzed and compared.

\section{Statistical Analysis and Data Treatment}

In order to provide reliable and quantifiable results, the collected data should be analyzed quantitatively first. Quantifiable results help to determine whether an improvement approach is worth the required investments or not.

The data presented for the thermal tooling optimization are analyzed by means of a $t$-test for independent means. Two separate tests are performed to firstly, determine if a statistically significant reduction in manufacturing time can be achieved and secondly, to evaluate whether the reduction in temperature differences throughout the molds is significant enough to provide an advantage compared to standard tooling technology. The $t$-test was chosen because it is a proven statistical method, able to meaningfully process small samples sizes (minimum sample size is three or more; compare Tables 3 and 4) as well as populations that differ slightly from the normal distribution (Aron, A., Coups \& Aron, E. N., 2011). Two essential requirements to conduct a $t$-test were fulfilled. First, the $t$-test assumes equal variances for both populations but is robust enough to provide sufficiently accurate results even for populations with slightly different variances (Aron, A., Coups \& Aron, E. N., 2011). Second, both populations (P1: optimized molds; P2: molds without any optimization) should be independent of each other and do not have any overlap.

The $t$-test has been performed using Microsoft $\mathrm{Excel}^{\mathrm{TM}}$ and the results as well as the necessary formulae are presented in the following section. The cut-off score is set to a $90 \%$ confidence because different molds were used for the individual optimization experiments. The differences between the molds already result in differing heat-up times which increase the standard deviation of both populations in the same way. As a result, the improvements achieved are not as clearly visible as in the case of identical reference molds for all experiments. The 
90\% confidence, however, is usually sufficient for industrial application (J.-C. Arent, Airbus Helicopters, personal communication, 2015).

The lack of precise, dependable, and comparable data on AFP manufacturing and production transfer to low-cost countries does not permit an analysis with statistical methods. For a correct statistical analysis, the test conditions must be known to enable a clear differentiation between the populations (Aron, A., Coups \& Aron, E. N., 2011). Therefore, the presented data will be analyzed by directly comparing the possible cost reductions.

\section{Results and Discussion}

The following sections comparatively present the results from literature review and the statistical evaluations. Each section contains a short discussion of the obtained results. Finally, an overall comparison of all possible improvement options is drawn.

\section{Tooling Optimization}

In order to evaluate the possible improvements by thermal tooling optimization the presented values in Table 1 are first compared graphically. If a certain tooling type offers more than one improvement option, only the best one is examined. Figure 5 shows that all optimizations reduce the heat-up time. The magnitude, however, depends on the type of mold. Especially, the Invar ${ }^{\circledR}(\mathrm{FeNi36})$ mold shows significant improvement after elimination of the thermos flasks, but the graphical analysis does not reveal whether the result is statistically significant or not.

Therefore, a $t$-test is performed in addition to the graphical analysis. Population one consists of the optimized molds, population two of standard molds without any optimizations (Mold C, Standard Configuration, Typical Helicopter Structure, Standard Configuration 2, and Standard Configuration Made of Invar®). If the mean of population one is significantly lower than the mean of population two, the heat-up times will be faster and, consequently, production time will be significantly lower. Yet, if no statistically significant difference between the two populations can be measured, the conclusion must be that the performed tooling optimizations are not sufficient to decisively improve manufacturing. 


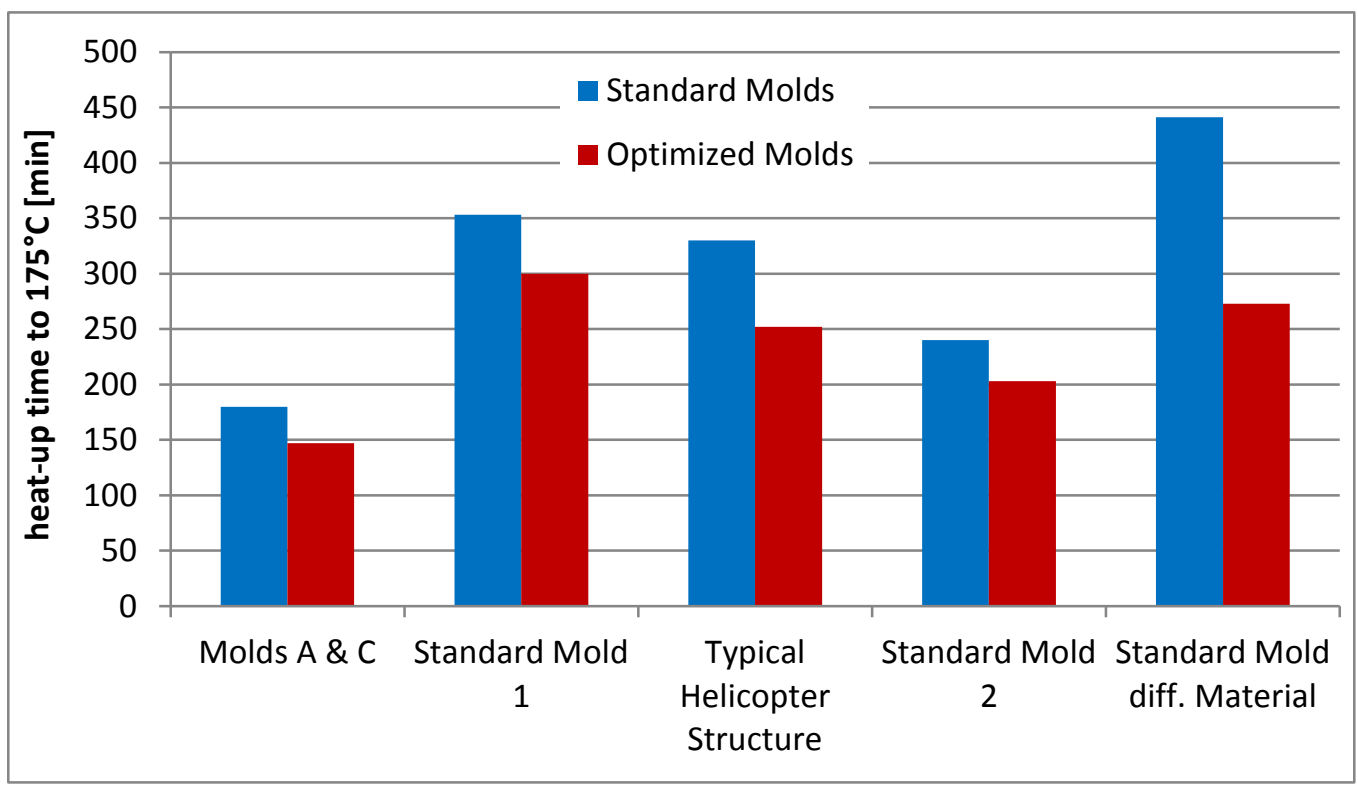

Figure 5. Graphical comparison of heat-up times for different mold configurations and optimizations

Table 3

T-test to determine a statistically significant reduction in manufacturing times

\begin{tabular}{|c|c|c|c|c|c|c|c|}
\hline \multirow[b]{2}{*}{ Variable } & \multicolumn{3}{|c|}{$\begin{array}{c}\text { Population } 1 \\
\text { Thermal Optimization }\end{array}$} & \multicolumn{3}{|c|}{$\begin{array}{c}\text { Population } 2 \\
\text { No Optimization }\end{array}$} & \multirow[b]{2}{*}{$t$} \\
\hline & $n$ & $M$ & $S D$ & $n$ & $M$ & $S D$ & \\
\hline $\begin{array}{l}\text { Heat-up } \\
\text { Time }\end{array}$ & 7 & 233.4 & 68.4 & 5 & 308.8 & 101.5 & -1.49 \\
\hline
\end{tabular}

The cut-off score for a one-tailed $t$-test at a .10 level and a total degree of freedom of ten is -1.372 (StatTrek.com, 2014). The test for reduced heat-up times in optimized models is statistically significant, $t(6,4)=-1.49, \mathrm{p}=0.076$. The null hypothesis is rejected and the research hypothesis is supported, i.e. the tooling optimizations result in a reduction of heat-up times and therefore in a significant reduction of manufacturing times. Figure 5 is supported by statistics and the results show a statistically significant reduction of heat-up times. A $15 \%$ to $38 \%$ reduction is possible, depending on the type of mold and the material selection.

Another aspect that was mentioned earlier is a possible quality improvement due to reduced temperature differences within the molds. This reduction leads to more homogeneous curing with less temperature and cure shrinkage induced 
internal stresses, which in turn increases the part quality and dimensional accuracy (Johnston, 1997; Svanberg, 2002). It has been argued that improving part quality will indirectly lower manufacturing times and especially manufacturing costs because the quality assurance program can be downsized. These improvements are analyzed graphically and statistically next.

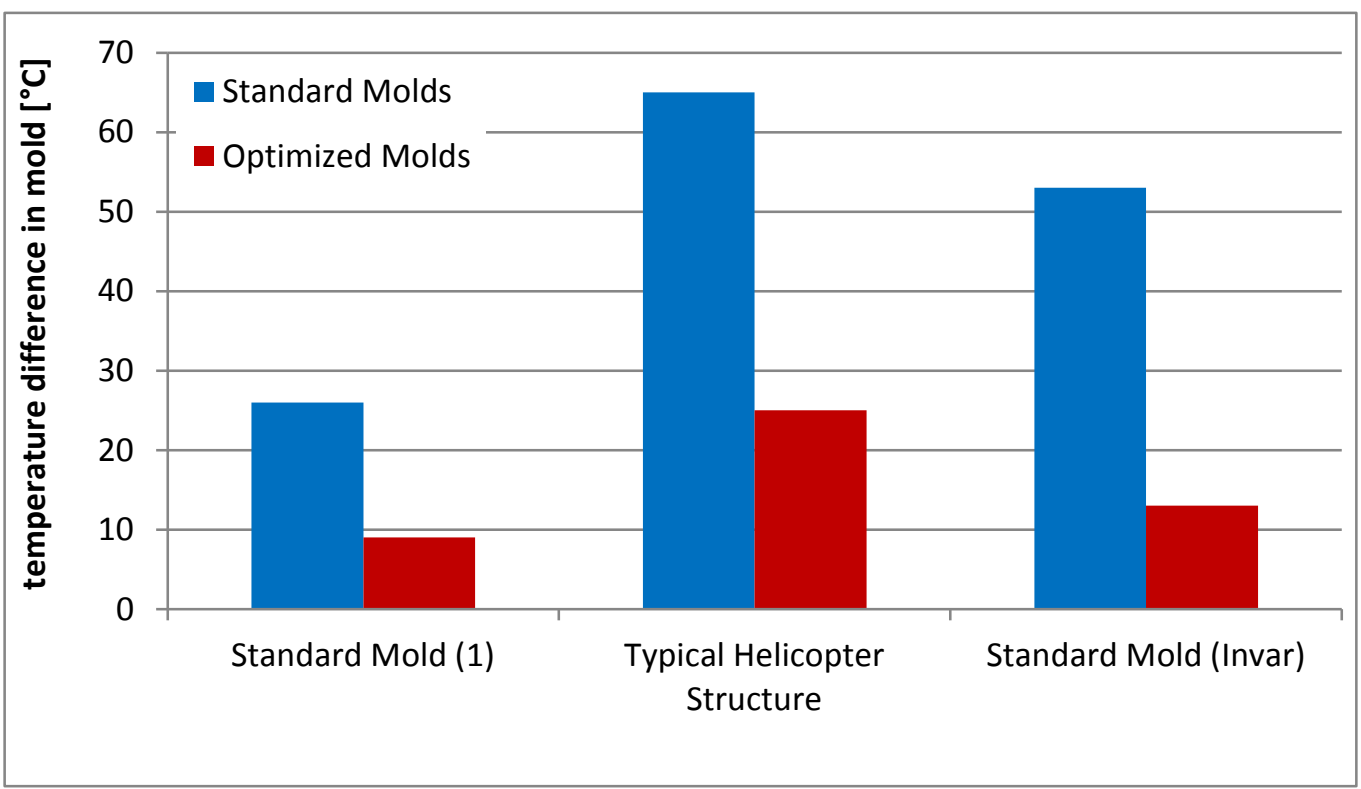

Figure 6. Graphical comparison of the temperature differences inside the analyzed molds

The graphical analysis of the data shows a large reduction of temperature differences between the standard mold configurations and the optimized versions of the same molds (Figure 6). A closer look at the values reveals that the reduction in temperature differences for all molds is approximately 65\%. However, Figure 6 does not reveal if the reduction is statistically significant or not.

Table 4

T-test to determine a statistically significant reduction in manufacturing times

\begin{tabular}{|c|c|c|c|c|c|c|c|}
\hline \multirow[b]{2}{*}{ Variable } & \multicolumn{3}{|c|}{$\begin{array}{c}\text { Population } 1 \\
\text { Thermal Optimization }\end{array}$} & \multicolumn{3}{|c|}{$\begin{array}{c}\text { Population } 2 \\
\text { No Optimization }\end{array}$} & \multirow[b]{2}{*}{$t$} \\
\hline & $n$ & $M$ & $S D$ & $n$ & $M$ & $S D$ & \\
\hline $\begin{array}{l}\text { Temperature } \\
\text { Difference }\end{array}$ & 4 & 15.3 & 6.8 & 3 & 48.0 & 20.0 & -2.87 \\
\hline
\end{tabular}


The cut-off score for a one-tailed $t$-test at a .10 level and a total degree of freedom of five is -1.476 (StatTrek.com, 2014). The test for reduced temperature differences in optimized models is statistically significant, $t(3,2)=-2.87, p=0.013$. The hypothesis of tooling optimizations resulting in a reduction of temperature differences within the mold is supported. In this case, even a .05 significance level can be achieved, which is more than required for industrial applications. The cutoff score at a .05 level is -2.015 , which is still higher than the -2.87 that resulted from the $t$-test.

However, the reduction in temperature differences of about $65 \%$ does not mean that a cost reduction of $65 \%$ will occur. In fact, the cost reduction will be rather small, since internal stresses caused by temperature gradients are only a minor quality issue (Svanberg, 2002). Unfortunately, no quantitative values are available at this point, because publications on tooling optimizations are rare (Weber, Arent, Steffens et al., 2016). Yet, it may be argued confidently that the higher the quality of the single parts, the higher will be the quality of the complete helicopter or airplane. Besides, quality improvements do not only reduce costs but also enhance a company's public image in terms of its orientation toward safety.

\section{Advanced Lay-up Routines and Automated Fiber Placement}

Since the reductions in manufacturing times for an improved lay-up routine are rather small, and the effect on manufacturing costs is mainly indirect from reduced training effort, there is no separate analysis of this approach. Instead, the more promising and farther reaching introduction of automated systems is analyzed in detail in the following section.

Evaluating possible reductions in manufacturing times that arise from the use of the AFP is more difficult than evaluating the results of tooling optimizations. First of all, the data available does not directly compare the manufacturing times of the same part manufactured by hand lay-up and by AFP. One reason might be that for the use of AFP, the lay-up or stacking sequence has to be altered. AFP can only process unidirectional tapes or fiber tows, while hand lay-up can also process woven fabric with two main fiber directions in one ply. Since helicopter parts use a lot of fabric material, a change in the stacking sequence must occur when transferring to AFP (J.-C. Arent, Airbus Helicopters, personal communication, 2015). From the values provided in the literature it can be deduced that approximately $54 \%$ to $85 \%$ of the manual labor are substituted by the automated processes of AFP. However, the overall manufacturing time for a certain part is a combination of manual labor, autoclave cycle time, demolding, mold cleaning, quality checks, and so on. This means that an $85 \%$ reduction of manual labor does 
not necessarily result in the same reduction in overall manufacturing time. Only the time needed to laminate the part is reduced by a factor of 3.75 to 4.5 . Besides, the gathered data does not reveal, whether the provided numbers $(54 \%$ to $85 \%$ reduction in manual labor) are focused on lamination work alone or if those numbers include the complete manual work required during part production (i.e. the application of a vacuum bag, cleaning of the mold, etc.). It seems impossible, hence, to deduce a quantitative value for time savings from the gathered data alone.

Apart from this, the reduction of manufacturing costs is highly dependent on the complexity of the manufactured part itself, which makes it even harder to provide a generalized answer to the question whether AFP is useful for the improvement of a certain production facility or not (Younossi et al., 2001). The available data does, however, show that - depending on the part's complexity - cost reductions between $10 \%$ and $43 \%$ are theoretically possible. While information about which costs are contained in this estimate is again absent, Dequine and Rush (2014) predict a $13 \%$ cost reduction for a simple shell structure with an additional $12.5 \%$ reduction in quality costs. This overall reduction of $25.5 \%$ is in between the predictions of Younossi et al. (2001) who state a possible reduction of $19 \%$ for medium complexity and $36 \%$ for low part complexity. It can be assumed that the higher estimates include the savings from quality costs, while the lower estimates only focus on savings from the reduction of manual labor. In sum, a mean possible cost reduction (incl. quality costs) of approximately $28 \%$ may be achieved, strongly depending on part type and complexity. Another factor, which has been discussed earlier, is the relationship of efficiency improvements and the number of parts produced. Since the given estimations provide only insufficient data about the included cost factors and the number of parts the estimate is based on, a generalized statement about the efficiency of AFP is not possible.

Comparing the introduction of AFP to the thermal tooling improvement, some conclusions can still be drawn. The AFP reduces the time necessary for lamination by a factor of $3.75(375 \%)$ to $4.5(450 \%)$. Since the time for part lamination takes about $54 \%$ to $85 \%$ of the complete manufacturing time, the time reductions through AFP are generally higher than those achievable with thermal tooling optimization. Additionally, the cost reductions with AFP are far greater than with thermal tooling optimization. AFP reduces the labor costs by at least $10 \%$ to $35 \%$. The reduction in energy costs from reduced autoclave cycle time is proportional to the time reduction and therefore about $15 \%$ to $38 \%$. Labor costs are generally higher than energy cost, i.e. the use of AFP will provide better cost savings than a tooling optimization. The additional savings in quality costs of $12.5 \%$ by AFP support this statement. There will be quality cost savings also for improved molds but their quantitative value is difficult to determine. Fewer 
deviations from the standard autoclave cycle will most certainly reduce the effort for quality control; fewer process induced deformations by reducing thermal stresses lower assembly costs. However, no quantitative estimations of these cost reductions could be found.

One major difference between the two approaches must be considered. Thermal tooling improvements can be implemented rather easily and at much lower costs than an AFP set-up. When AFP is introduced in the production process, the part design, the complete production facility, manufacturing processes, molds, materials, etc. must be adjusted to its use. These steps add to the investment for establishing the AFP system itself, which can be as high as US $\$ 6 \mathrm{M}$ as stated by Goel (2000). The costs of a thermal tooling optimization are much lower, because the optimization is carried out during the virtual design phase of the mold. Even a doubling of the tooling costs for a large, complex mold will stay well below US \$1M (J.-C. Arent, Airbus Helicopters, personal communication, 2015), which makes tooling improvement an attractive option; even if the overall achievable manufacturing cost reductions are lower.

\section{Low-cost Countries and Make-or-buy Decision Making}

As discussed earlier, if thermal tooling improvement or AFP does not achieve the targeted cost reductions, the production might be shifted to a country with lower labor costs. Manual labor accounts for about $42 \%$ of production costs in hand lay-up processes, which means that a total reduction of production costs of about $26 \%$ to $28 \%$ could be achieved through the lower hourly rates in countries such as Mexico and China as described above.

Yet, the discussion above revealed a number of potentially negative factors such as complex, just-in-time logistics to include specialized transportation, the risk of transportation and resulting interruptions at the final assembly line. In addition, the required investment into production facilities at a new location may be as high as - or even higher than - the investment in an AFP system at home.

In the alternative case of buying parts in low-cost countries, the logistical problems remain nonetheless, but the necessary investment for a new production facility can be avoided. As the earlier discussion has shown, further savings may be achieved in this case by more efficient production methods of specialized suppliers.

Taking all these factors into account, a generalized recommendation whether to shift the production to low-cost countries or to buy parts from 
specialized suppliers is impossible. Similar to AFP, it is necessary to evaluate each case carefully, weighing all factors such as logistics, part complexity, the number of parts per year, available technologies, and the performance of available suppliers. One noteworthy conclusion, however, can be made at this point: Investing in AFP may result in a similar cost-benefit ratio as the production shift to a low-cost country.

\section{Comparison of the Three Methods}

The following table shows a detailed comparison of all three options to improve the production process for more efficiency. The discussions above were subsumed as either a negligible, considerable, or decisive improvement of efficiency. In addition, the necessary investment is estimated on a low to large scale, including remarks where necessary.

\section{Recommendations}

A statistically significant reduction in manufacturing times and quality problems was found for the thermal tooling improvement. The reduction in autoclave cycle time of approximately $15 \%$ to $38 \%$ can be achieved with minimal investment. A significant reduction in temperature gradients within the mold will increase the part quality and thus reduce quality costs. Although the cost reduction might be small, the advantages of thermal tooling improvement are obvious. Only small preceding investments are needed to reduce quality issues and increase production rates. These improvements are supported quantitatively, which makes them the most promising option. As a result, thermal tooling optimization can be recommended for all autoclave manufacturing sites, independent of part complexity or the number of parts produced per year.

At the onset of this paper it was hypothesized that AFP would show to be the best solution for the manufacturing of composite parts. After closer investigation of available data within the scope of this project, the outcome is rather different. It has become clear that potential improvements with the AFP system depend on a lot of factors, to include part complexity, the number of parts to be produced, the type of AFP equipment, and the type of prepreg used. A possible cost reduction ranges from $10 \%$ to $43 \%$ plus additional savings of up to $12.5 \%$ from reduced quality costs were provided by different sources. In summary, it is difficult to formulate a general statement about the benefits of AFP systems. Yet it can be determined that cost savings decrease, when the complexity of the manufactured part increases. 
On the other hand, AFP systems are increasingly advantageous over manual lay-up processes with a rising number of parts to be produced. The introduction of AFP, however, is extremely costly. It is recommended to closely analyze the current production situation and possible further developments before investing into AFP. A company that decides to work with AFP must ensure that the new system can operate at full capacity, i.e. the demand for new helicopters or airplanes needs to exceed the manual lay-up rate, and the parts must be large and simple enough to ensure that the AFP can work at full material deposition rates. Only in this case does the investment for an AFP system seem appropriate, because otherwise the cost reduction might not compensate the investment in an appropriate time frame.

Out-sourcing is often an inadequate response to seemingly inefficient manufacturing processes, if the potential of the manufacturing processes in question is not fully understood (Shorten et al., 2006). Before an out-sourcing by transferring of work to low-cost countries or by buying parts from suppliers is contemplated, the current processes should be analyzed carefully to determine the actual potential for improvements. An example is the thermal tooling optimization that was presented earlier. If such improvements are possible without large investments, they should be favored. This recommendation is supported by Shorten et al. (2006) who state that a company should conduct a thorough and objective evaluation of its core competencies to explore their improvement potential. In short, when the in-house improvement potential is completely exhausted, an outsourcing might be the reasonable way for further cost reductions.

The simple transfer of a current production process to another country cannot be recommended without considering technological improvements. If a given production set-up is simply transferred, labor costs might be reduced, but overall time and quality issues might increase because of additional logistical efforts and lower worker experience. It is recommended that the plan for investment in a new production site should automatically include the introduction of technological improvements like thermal tooling optimization or the use of an AFP system, if part complexity and production rates permit. 
Table 5

Comparison of costs between hand lay-up and AFP (adapted from Younossi et al., 2001)

\begin{tabular}{|c|c|c|c|c|}
\hline $\begin{array}{l}\text { Improvement } \\
\text { Option }\end{array}$ & $\begin{array}{l}\text { Possible Cost } \\
\text { Reduction }\end{array}$ & $\begin{array}{l}\text { Possible Time } \\
\text { Reduction }\end{array}$ & $\begin{array}{l}\text { Possible Quality } \\
\text { Improvement }\end{array}$ & $\begin{array}{l}\text { Necessary } \\
\text { Investment }\end{array}$ \\
\hline $\begin{array}{l}\text { Thermal } \\
\text { Tooling } \\
\text { Optimization }\end{array}$ & $\begin{array}{l}\text { considerable } \\
\text { no quantitative value } \\
\text { available but below } \\
\text { AFP since energy } \\
\text { costs are generally } \\
\text { lower than labor cost }\end{array}$ & $\begin{array}{l}\text { considerable } \\
15 \% \text { to } 38 \% \\
\text { reduction of } \\
\text { autoclave cycle } \\
\text { time }\end{array}$ & negligible & $\begin{array}{l}\text { very low } \\
\text { implemented } \\
\text { into tooling } \\
\text { design process }\end{array}$ \\
\hline AFP & $\begin{array}{l}\text { decisive } \\
10 \% \text { to } 43 \% \text { of the } \\
\text { overall production } \\
\text { costs } \\
\text { mean of } 28 \% \text { but } \\
\text { highly depending on } \\
\text { part complexity and } \\
\text { number of parts } \\
\text { produced per year }\end{array}$ & $\begin{array}{l}\text { decisive } \\
375 \% \text { to } 450 \% \\
\text { reduction of the } \\
\text { time needed for } \\
\text { lamination } \\
\text { time of manual } \\
\text { labor is } 54 \% \text { to } \\
85 \% \text { of total } \\
\text { production time, } \\
\text { i.e., a greater } \\
\text { time reduction } \\
\text { is achievable } \\
\text { than with } \\
\text { thermal tooling } \\
\text { optimization } \\
\text { with its focus on } \\
\text { the reduction of } \\
\text { the autoclave } \\
\text { cycle time }\end{array}$ & $\begin{array}{l}\text { considerable } \\
\text { approximately } \\
12.5 \% \text { of the } \\
\text { quality costs can } \\
\text { be reduced } \\
\text { rejection rates are } \\
\text { below hand lay- } \\
\text { up }\end{array}$ & $\begin{array}{l}\text { large } \\
\text { new machinery, } \\
\text { new production } \\
\text { processes }\end{array}$ \\
\hline $\begin{array}{l}\text { Shift of } \\
\text { Production } \\
\text { to Low-cost } \\
\text { Country }\end{array}$ & $\begin{array}{l}\text { decisive } \\
\text { up to } 28 \%\end{array}$ & $\begin{array}{l}\text { none } \\
\text { possible time } \\
\text { increase due to } \\
\text { needed logistics }\end{array}$ & $\begin{array}{l}\text { none } \\
\text { production } \\
\text { method is not } \\
\text { altered }\end{array}$ & $\begin{array}{l}\text { large } \\
\text { new facility, } \\
\text { necessary means } \\
\text { of transportation }\end{array}$ \\
\hline $\begin{array}{l}\text { Buying from } \\
\text { Supplier in } \\
\text { Low-cost } \\
\text { Country }\end{array}$ & $\begin{array}{l}\text { decisive } \\
\text { in the range of } \\
\text { shifting the } \\
\text { production to low- } \\
\text { cost countries }\end{array}$ & $\begin{array}{l}\text { unknown } \\
\text { depends on } \\
\text { manufacturing } \\
\text { process at } \\
\text { supplier }\end{array}$ & $\begin{array}{l}\text { unknown } \\
\text { depends on } \\
\text { manufacturing } \\
\text { process at } \\
\text { supplier }\end{array}$ & $\begin{array}{l}\text { medium } \\
\text { logistics only }\end{array}$ \\
\hline
\end{tabular}

In summary, a combination of the improvement approaches presented here should produce the best possible result. Thermal tooling improvement can be done with minimal investment and will reduce the autoclave cycle time as well as the quality issues arising from uneven curing. Improving manual lay-up by either 
optimizing the lay-up routine or implementing an AFP system (depending on production rates and part complexity) will reduce time and costs for the lamination process. Further cost reductions can then be achieved by out-sourcing simple parts or very specialized parts to sub-contractors located in low-cost countries or having a very specialized production process for the part in question. This combination of improvement approaches promises the best possible outcome with the lowest investment required.

\section{Conclusion}

Automated prepreg lamination, thermal tooling optimization, and the transfer of composite production capacities to low-cost countries directly correlate with a significantly reduced manufacturing effort and an increased quality of composite helicopter parts. Therefore, the research hypothesis can generally be accepted. For thermal tooling optimization, statistically significant reductions of manufacturing times and quality issues were found, while for other areas of improvement only estimates could be made. The data obtained does not allow generalized recommendations based on quantitative evaluations of the effectiveness of the different improvement options. Although tooling improvement is a good way to start production improvement, a thorough analysis of the actual circumstances in a company must be performed to find the right approach for further innovations. 


\section{References}

Airbus (n.d.a). Transport of major aircraft sections. Retrieved from http://www.airbus.com/company/aircraft-manufacture/how-is-an-aircraftbuilt/transport-of-major-aircraft-sections/

Airbus (n.d.b). Carrying outsized cargo quickly and efficiently. Retrieved from http://www.airbus.com/aircraftfamilies/freighter/beluga/economics/

Aron, A., Coups, E., \& Aron, E. N. (2011). Statistics for the behavioral and social sciences: A brief course (5th ed.). Essex, UK: Pearson Education Limited

Brauner, L. (2013). Analysis of process-induced distortions and residual stresses of composite structures (Doctoral dissertation). Berlin, Germany: Logos Verlag

Clarke, C. (2015, October 8). An extraordinary time-lapse of Boeing assembling the Dreamliner. Popular Mechanics. Retrieved from http://www.popularmechanics.com/flight/a17711/time-lapse-boeingassembling-dreamliner/

Committee on the Offshoring of Engineering (2008). The offshoring of engineering: Facts, unknowns, and potential implications. Retrieved from http://www.nap.edu/catalog/12067.html

Cremer, A. (2016, August 17). VW's key plant hit by parts shortage in supplier row. Reuters Business News. Retrieved from http://www.reuters.com/article/us-volkswagen-productionidUSKCN10S2BR

Crowley, D., Jones, H., Elkington, M., Bloom, D., Such, M., Kalaratna, S., Potter, K., \& Ward, C. (2015). Capturing knowledge and exploiting human factors to improve on advanced composite manufacturing. Proceedings of the SAMPE Europe Conference, Amiens, France. Retrieved from http://www.sampe-europe.org/library/

Dassault Systems (2014, August 17). Energy, process \& utilities: Sustainable wind turbines -faster time-to-market with improved reliability and lower cost. Retrieved from http://www.3ds.com/fileadmin/Industries/EnergyProcess-Utilities/Pdf/brochures/EPU-SWT-A4WEB-solution-brief-v2.pdf 
Dequine, D. L., \& Rush, C. (2014). Continuous fiber composite part cost vs production volume by manufacturing process and material. El Segundo, CA: Lockheed Martin. Retrieved from http://www.iceaaonline.com/ready/wp-content/uploads/2015/01/ChrisRush-SoCal-ICEAA-Dec-2014.pdf

Elkington, M., Bloom, D., Ward, C., Chatzimichali, A., \& Potter, K. (2015). Hand layup: Understanding the manual process. Advanced Manufacturing: Polymer \& Composite Science, 1, 128-141. doi: 10.1080/20550340.2015.1114801

Goel, A. (2000). Economics of composite material manufacturing equipment (Bachelor's thesis, Massachusetts Institute of Technology). Retrieved from http://dspace.mit.edu/bitstream/handle/1721.1/31096/48412282MIT.pdf;sequence=2

Goetsch, D. L. (2014). Occupational safety and health: For technologists, engineers, and managers ( $8^{\text {th }}$ ed.). Harlow, UK: Pearson Education Limited.

Grimshaw, M. N., Grant, C. G., \& Diaz, J. M. L. (n.d.). Advanced technology tape laying for affordable manufacturing of large composite structures.

Retrieved from https://pdfs.semanticscholar.org/09d2/e6f8d7608f5ba980bc83efaaf92cd36d c3c6.pdf

Hoa, S. V. (2014). Automated composites manufacturing. Paper presented at the Advanced Materials International Forum, Bari, Italy. Retrieved from http://www.sistema.puglia.it/portal/pls/portal/sispuglia.ges_blob.p_retrieve? p_tname=sispuglia.documenti\&p_cname $=$ testo $\&$ p_cname_mime $=$ mime_typ e_testo\&p_rowid=AAAh67AAVAALycLAAC\&p_esito=0

Hudek, M. (2001). Examination of heat transfer during autoclave processing of polymer composites (Master's thesis, University of Manitoba, Canada). Retrieved from http://mspace.lib.umanitoba.ca/xmlui/bitstream/handle/1993/18877/Hudek_ Examination_of.pdf?sequence=1\&isAllowed=y 
Hull, R. (2016, August 25). Volkswagen resumes production at Golf and Passat plants as dispute with suppliers is resolved. Daily Mail, UK. Retrieved from http://www.dailymail.co.uk/money/cars/article-3756477/VW-resolvesdispute-parts-suppliers-slowed-car-production.html

Jacobs, F. R., \& Chase, R. B. (2011). Operations and supply chain management ( $3^{\text {rd }}$ ed.). New York: McGraw-Hill Irwin

Johnston, A. (1997). An integrated model of the development of process-induced deformations in autoclave processing of composite structures (Doctoral dissertation, University of British Columbia). Retrieved from https://open.library.ubc.ca/cIRcle/collections/ubctheses/831/items/1.008880 5

Koehler, T. (2005). Supersize. Boeing Frontiers, 4(2). Retrieved from http://www.boeing.com/news/frontiers/archive/2005/june/ts_sf05.html

Kollmannsberger, A. (n.d.). Automated fiber placement. Technical University of Munich. Retrieved from http://www.lcc.mw.tum.de/en/researchgroups/process-technology-for-fibers-and-textiles/automated-fiberplacement/

Lichtinger, R. (2014). Thermal simulation of the automated fiber placement process and its validation. Paper presented at the CFK-Valley Stade Convention. LLC, Technical University of Munich. Retrieved from http://www.cfkconvention.com/fileadmin/Convention_2014/Referenten/Vortraege/CFK_C onv2014_Lichtinger.pdf

Lightfoot, J. S. (2013). Mechanisms of defect formation in carbon fibre composites (Doctoral dissertation, University of Bristol, UK). Retrieved from http://ethos.bl.uk/OrderDetails.do?uin=uk.bl.ethos.619140

Lindbäck, J. E., Björnsson, A., \& Johansen, K. (2012). New automated composite manufacturing process: Is it possible to find a cost effective manufacturing method with the use of robotic equipment. Proceedings of the $5^{\text {th }}$ International Swedish Production Symposium, 523-531. Retrieved from http://liu.diva-portal.org/smash/get/diva2:568097/FULLTEXT01.pdf 
Lukaszewicz, D. H.-J.A., Ward, C., \& Potter, K. D. (2012). The engineering aspects of automated prepreg layup: History, present and future.

Composites: Part B, 43, 997-1009. doi: 10.1016/j.compositesb.2011.12.003

Ma, W. (2011). Cost modelling for manufacturing of aerospace composites (Master's thesis, Cranfield University, UK). Retrieved from https://dspace.lib.cranfield.ac.uk/bitstream/1826/6279/1/Ma_Weitao_Thesis _2011.pdf

Mazarro, A., \& Garcia, A. (2016). Tooling optimization for composite material parts. Paper presented at the European Congress on Composite Materials 17, Munich, Germany.

Mrazova, M. (2013). Advanced composite materials of the future in aerospace industry. Incas Bulletin, 5(3), 139-150. doi: 10.13111/20668201.2013.5.3.14

Occupational Safety \& Health Administration (n.d.). OSHA Technical Manual (OTM), Section III: Chapter 1. Retrieved from https://www.osha.gov/dts/osta/otm/otm_iii/otm_iii_1.html

Osborne, T. (2015, March 3). Airbus removes veil from H160 project. Aviation week \& Space Technology. Retrieved from $\mathrm{http} / / /$ aviationweek.com/business-aviation/airbus-removes-veil-h160 -project?eid=forward

Red, C. (2008, March 1). Aviation outlook: Composites in rotorcraft reaching new altitudes. Composites World. Gardner Business Media, Cincinnati, OH. Retrieved from http://www.compositesworld.com/articles/aviation-outlookcomposites-in-rotorcraft-reaching-new-altitudes

Salas, E., \& Maurino, D. (Eds.). (2010). Human factors in aviation ( $2^{\text {nd }}$ ed.). New York: Academic Press.

Schubel, P.J. (2012). Cost modelling in polymer composite applications: Case study - Analysis of existing and automated manufacturing processes for a large wind turbine blade. Composites: Part B, 43, 953-960.

doi: 10.1016/j.compositesb.2011.11.036 
Shama Rao, N., Simha, T. G. A., Rao, K. P., \& Ravikumar, G. V. V. (2015). Whitepaper: Carbon composites are becoming competitive and cost effective. External document, Infosys Ltd., Bangalore, India. Retrieved from https://www.infosys.com/engineering-services/whitepapers/Documents/carbon-composites-cost-effective.pdf

Shorten, D., Pfitzmann, M., \& Kaushal, A. (2006). Make versus buy: A decision framework. Retrieved from http://www.strategyand.pwc.com/media/uploads/MakeVersusBuy.pdf

Sikorsky (2016). CH-53K Helicopter: The world's premier heavy lift helicopter is in development at Sikorsky. Retrieved from http://www.sikorsky.com/Pages/Products/Military/CH53/CH53K.aspx

Sloan, J. (2015, December 7). Flightware wins AFP inspection development contract. Composites World. Gardner Business Media, Cincinnati, $\mathrm{OH}$. Retrieved from http://www.compositesworld.com/news/flightware-winsafp-inspection-development-contract

StatTrek.com (2014). T distribution calculator: Online statistical table. Retrieved from http://stattrek.com/online-calculator/t-distribution.aspx

Svanberg, J. M. (2002). Predictions of manufacturing induced shape distortions high performance thermoset composites (Doctoral dissertation, Lulea University of Technology, Sweden). Retrieved from http://epubl.ltu.se/1402-1544/2002/40/LTU-DT-0240-SE.pdf

Telikicherla, M. K., Altan, M. C., \& Lai, F. C. (1994). Autoclave curing of thermosetting composites: Process modeling for the cure assembly. International Community of Heat and Mass Transfer, 21(6), 785-797. doi: 10.1016/0735-1933(94)90032-9

Thompson, P. (2015, February 3). On the wings of giants: Airbus banks on the Beluga. NYC Aviation. Retrieved from http://www.nycaviation.com/2015/02/wings-giants-airbus-banks-beluga/

University of Cambridge, UK (2001). Industrial make-or-buy decisions (Research project). Retrieved from: http://www.ifm.eng.cam.ac.uk/research/csp/mvb/

U.S. Department of Labor (n.d.). Night work \& shift work. Retrieved from https://www.dol.gov/general/topic/workhours/nightwork 
Vestring, T., Rouse, T., Reinert, U., \& Varma, S. (2005). Making the move to lowcost countries. Bain \& Company. Retrieved from http://bain.com/bainweb/PDFs/cms/Public/BB_Making_move_lowcost_countries.pdf

Wang, X., Zhang, Z., Xie, F., Li, M., Dai, D., \& Wang, F. (2009). Correlated rules between complex structure of composite components and manufacturing defects in autoclave molding technology. Journal of Reinforced Plastics and Composites, 28(22). doi: 10.1177/0731684408093876

Weber, T., A., Arent, J-C., Münch, L., Duhovic, M., \& Balvers, J. M. (2016). A fast method for the generation of boundary conditions for thermal autoclave simulation. Composites: Part A, 88, 216-225. doi: 10.1016/j.compositesa.2016.05.036

Weber, T. A., Arent, J-C., Steffens, L., Balvers, J. M., \& Duhovic, M. (2016). Thermal optimization of composite autoclave molds using the shift factor approach for boundary condition estimation. Manuscript submitted for publication.

Weber, T., \& Balvers, J. M. (2015). Manufacturing process simulation for tooling optimization: Reduction of quality issues during autoclave manufacturing of composite parts. Paper presented at the SAMPE Europe Conference, Amiens, France.

Weimer, C. (2014). Composites in aerospace - future challenges, needs and opportunities. Paper presented at the Institute for Carbon Composites Symposium, Garching, Germany. Retrieved from http://www.lcc.mw.tum.de/fileadmin/w00bkg/www/PDF/Symposium/LCC_ Symposium_Weimer.pdf

Wensveen, J. G. (2007). Air transportation: A management perspective ( $6^{\text {th }}$ ed.). Burlington, VT: Ashgate Publishing.

Wiedemann, M., \& Sinapius, M. (Eds.). (2012). Adaptive, tolerant and efficient composite structures. Berlin, Heidelberg: Springer 
Xie, G., Liu, J., Zhang, W., Lovenzini, G., \& Biserni, C. (2013). Simulation and improvement of temperature distributions of a framed mold during autoclave composite process. Journal of Engineering Thermophysics, 22, 43-61. doi:10.1134/S1810232813010062

Younossi, O., Kennedy, M., \& Graser, J. C. (2001). Military airframe costs: The effects of advanced materials and manufacturing processes. Santa Monica, CA: RAND Corporation 